\title{
PERENCANAAN STRUKTUR ATAS ASRAMA PUTRI DI UNIVERSITAS KADIRI
}

\author{
Renaldi Oza Purbawa ${ }^{* 1}$, Ahmad Ridwan ${ }^{2}$, Yosef Cahyo SP. ${ }^{3}$ \\ ${ }^{1}$ Fakultas Sipil, Universitas Kadiri \\ e-mail :*1oza1995@gmail.com, 2ªhmad_ridwan@unik-kediri.ac.id \\ 3yosef.cs@unik-kediri.ac.id
}

\begin{abstract}
In this superstructure planning, many methods can be used to calculate the moment, one of which is the ultimate moment calculation method, with reference to SK SNI 2847.2013. For pouring, images can be presented with AutoCAD software. The results of this plan are, for the roof and floor plates, a thickness of $100 \mathrm{~mm}$ and $120 \mathrm{~mm}$ is used with $12 \mathrm{~mm}$ of principal reinforcement and $8 \mathrm{~mm}$ of stirrups with a distance of $200 \mathrm{~mm}$. For beam and sloof, they are used the same, namely $16 \mathrm{~mm}$ for the main reinforcement and $10 \mathrm{~mm}$ for the stirrup reinforcement with a distance of $200 \mathrm{~mm}$ for columns used 16 $\mathrm{mm}$ reinforcement and $12 \mathrm{~mm}$ stirrups with a distance of $200 \mathrm{~mm}$. The load distribution for the roof floor is 20,640,924 kgm, because the assumption of the 1st to 6th-floor loading is the same, which is $23,233,644 \mathrm{kgm}$. The moment in this planning is $17,074,370 \mathrm{kgm}$ on the plate, 342,733,875 $\mathrm{kgm}$ in the beam and 493,536,780 kgm. In the column, there is a moment that is large enough, with a value of $551,697,600 \mathrm{kgm}$. From the calculation of the earthquake load, the result is $=159843(\mathrm{kNm})$.
\end{abstract}

Keywords : Planning, Structure, CAD, SNI

\begin{abstract}
Abstrak
Dalam perencanaan struktur atas ini, banyak metode yang bisa dipakai untuk menghitung momen, salah satunya dengan metode perhitungan momen ultimit, dengan acuan SK SNI 2847,2013. Untuk penuangan gambar dapat disajikan dengan software AutoCAD. Hasil dari perencanaan ini adalah, untuk pelat atap dan lantai digunakan tebal $100 \mathrm{~mm}$ dan $120 \mathrm{~mm}$ dengan tulangan yang dipakai tulangan pokok $12 \mathrm{~mm}$ dan tulangan Sengkang $8 \mathrm{~mm}$ dengan jarak $200 \mathrm{~mm}$. Untuk balok dan sloof digunakan sama, yaitu $16 \mathrm{~mm}$ untuk tulangan pokok dan $10 \mathrm{~mm}$ untuk tulangan Sengkang dengan jarak $200 \mathrm{~mm}$. Untuk kolom digunakan tulangan $16 \mathrm{~mm}$ dan Sengkang $12 \mathrm{~mm}$ dengan jarak $200 \mathrm{~mm}$. Distribusi beban untuk lantai atap sebesar 20.640,924 kgm, karena asumsi pembebanan lantai 1 ke 6 adalah sama, yaitu sebesear 23.233,644 kgm. Momen pada perencanaan ini adalah pada pelat terjadi sebesar 17.074,370 kgm, pada balok terjadi sebesar $342.733,875 \mathrm{kgm}$ dan 493.536,780 kgm. Pada kolom timbul momen yang cukup besar, dengan nilai 551.697,600 kgm. Dari perhitungan beban gempa di dapatkan hasil $=159843(\mathrm{kNm})$.
\end{abstract}

Kata Kunci : Perencanaan, Struktur, CAD, SNI 


\section{PENDAHULUAN}

\subsection{Latar Belakang}

Indonesia sebagai negara yang sedang berkembang saat ini, diharapkan selalu berupaya meningkatkan pembangunan dalam berbagai sektor. Guna tercapainya tujuan umum ini, setidaknya seluruh bangsa turut memberikan dukungan. Kota Kediri sebagai eks-karesidenan yang menggabungkan 7 kota dan kabupaten sekitar dituntut mampu membangun sarana pendidikan yang memadai dan mampu bersaing. Ada beberapa universitas yang ada di kota Kediri, diantaranya adalah Universitas Kadiri yang menyediakan berbagai macam jurusan. Guna menunjang sarana menuntut ilmu tentu harus diimbangi dengan prasarana yang memadai. Misalnya sebagai tempat tinggal untuk mahasiswa dari jauh atau luar daerah, sehingga tidak kerepotan mencari tempat tinggal yang dekat. Universitas harus menyediakan setidaknya asramauntuk perempuan dan laki-laki secara terpisah. Dari uraian di atas, maka penulis mencoba untuk merencanakan struktur atas yang diperlukan untuk pembangunan asrama perempuan 7 lantai, dengan luas bangunan $600 \mathrm{~m}^{2}$ yang berukuran $30 \mathrm{~m}$ (Panjang) x 20m (Lebar).

\subsection{Identifikasi Masalah}

Berdasarkan latar belakang diatas terdapat rumusan masalah yaitu Berapa distribusi beban yang terjadi pada konstruksi asrama tersebut, Berapa momen pelat, balok, dan kolom yang terjadi, serta Bagaimana penulangan yang baik dan aman untuk pelat lantai, balok, kolom, dan sloof[1][2]. Adapun batasan masalah yaitu Perhitungan struktur, Perhitungan pelat lantai, balok, dan kolom, Asumsi pembebanan untuk pelat atap, Perhitungan momen menggunakan momen ultimit, serta Lantai 3 keatas menggunakan kolom praktis $20 \mathrm{~cm}$ x $25 \mathrm{~cm}$ [3][4]. Sedangkan maksud dan tujuannya adalah diharapkan mahasiswa teknik dapat mengetahui dan mampu untuk menghitung nilai distribusi beban 1 yang terjadi, menghitung nilai momen yang terjadi pada pelat, balok, dan kolom, serta menghitung penulangan yang aman dan efektif untuk pelat lantai, balok, dan kolom[5].

\section{METODE PENELITIAN}

\section{$2.1 \quad$ Struktur}

Struktur adalah bagian-bagian yang membentuk bangunan seperti pondasi, sloof, dinding, kolom, ring, kuda-kuda, dan atap[6]. Pada prinsipnya, elemen struktur berfungsi untuk mendukung keberadaan elemen nonstruktur yang meliputi elemen tampak, interior, dan detail arsitektur sehingga membentuk satu kesatuan[7]. Setiap bagian struktur bangunan tersebut juga mempunyai fungsi dan peranannya masing-masing. Struktur bawah (sub struktur) adalah bagian-bagian bangunan yang terletak di bawah permukaan tanah[8][9]. Struktur bawah ini meliputi pondasi dan sloof. Struktur tengah merupakan bagian-bagian bangunan yang terletak di 
atas permukaan tanah dan di bawah atap, serta layak ditinggali oleh manusia. Yang dimaksud struktur tengah di antaranya dinding, kolom, dan ring. Struktur atas (superstruktur) yaitu bagianbagian bangunan yang terbentuk memanjang ke atas untuk menopang atap. Struktur atas bangunan antara lain rangka dan kuda-kuda[10].

\subsection{Acuan Perencanaan}

Dalam perencanaan, pedoman yang digunakan ada 2 yaitu Tata cara perhitungan struktur beton untuk bangunan gedung dan Tata cara perencanaan pembebanan untuk rumah dan gedung.

\subsection{Peraturan Perencanaan}

Apabila kita akan merencanakan suatu bangunan, sudah tentu kita harus memperhatikan serta memperhitungkan segala aspek yang berhubungan dengan bangunan tersebut. Dengan kata lain, jika kita merencanakan suatu bangunan, kita dituntut dalam hal kesempurnaan bangunan itu sendiri. Untuk memenuhi hal tersebut, kita harus berpedoman pada syarat-syarat yang telah ditentukan baik dari segi teknis itu sendiri maupun dari segi lainnya.

\subsection{Peraturan Perhitungan Konstruksi}

Peraturan perhitungan konstruksi antara lain, Peraturan Perencanaan Bangunan Baja Indonesia (PPBBI 1984) dan Struktur Beton Bertulang Indonesia (SK SNI 2847-2013)[11].

\subsection{Dasar Perhitungan Konstruksi}

Dasar perhitungannya yaitu Konstruksi diperhitungkan terhadap pembebanan sementara serta Perhitungan mekanika pada konstruksi pelat dan konstruksi balok anak[12].

\subsection{Spesifikasi Teknik}

Spesifikasi tekniknya meliputi Mutu beton $\mathrm{fc}^{\prime}=25 \mathrm{MPa}$ dan Mutu tulangan baja fy $=240$ $\mathrm{Mpa}[13]$.

\subsection{Tuntutan dan Ketentuaan Umum Perencanaan}

Tuntutan atau ketentuan umum dalam perencanaan gedung yang harus kita perhatikan antara lain, Konstruksi harus aman, kokoh, kuat, baik terhadap pengaruh cuaca, iklim maupun terhadap pengaruh lainnya[14][15]. Bangunan harus benar-benar dapat berfungsi menurut penggunaannya. Ditinjau dari segi biaya, bangunan harus seekonomis mungkin dengan catatan tidak boleh mengurangi kekuatan konstruksi, sehingga tidak membahayakan bangunan dan keselamatan pengguna bangunan[16]. Dengan merencanakan bangunan ini kita usahakan jangan 
sampai membahayakan atau merugikan lingkungan, baik ketika masih dalam taraf pengerjaan maupun setelah bangunan itu digunakan atau selesai dikerjakan[17].

\subsection{Pembebanan}

Dalam perencanaan struktur atasperlu memperhatikan beban yang terjadi, antara lain Peraturan Pembebanan Indonesia untuk Gedung 1983, diterbitkan oleh Departemen Pekerjaan Umum Dirjen Cipta Karya Direktorat Penyidikan dan Pedoman Tata Cara Perencanaan Ketahanan Gempa untuk Rumah dan Gedung[18].

\subsection{Macam Pembebanan}

\subsubsection{Beban Mati (qd)}

Beban mati adalah berat dari semua bagian dari suatu gedung yang bersifat tetap, termasuk segala unsur tambahan, penyelesaian-penyelesaian, mesin - mesin serta peralatantetap yang merupakan bagian tak terpisahkan dari gedung itu(Peraturan Pembebanan Indonesia Untuk Gedung, 1983)[19].

\subsubsection{Beban Hidup (ql)}

Beban hidup adalah semua beban yang terjadi akibat penghuni atau pengguna suatu gedung, termasuk beban - beban pada lantai yang berasal dari barang - barang yang dapat berpindah, mesin - mesin serta peralatan yang merupakan bagian yang tidak terpisahkan dari gedung dan dapat diganti selama masa hidup dari gedung itu, sehingga mengakibatkan perubahan pembebanan lantai dan atap tersebut. Khususnya pada atap, beban hidup dapat termasuk beban yang berasal dari air hujan[20][21].

\subsubsection{Beban Angin (W)}

Beban Angin adalah semua beban yang bekerja pada gedung atau bagian gedung yang disebabkan oleh selisih dalam tekanan udara $(\mathrm{kg} / \mathrm{m} 2$.

\subsubsection{Beban Gempa (E)}

Pada Tugas Akhir ini pengaruh gempa diperhitungkan atas dasar analisa statis mengingat tinggi struktur 10,8 m. Gaya gempa yang bekerja pada sistem struktur diasumsikan sebagai gaya frontal (lateral horisontal) yang bekerja pada setiap lantai gedung [10][7].

\subsection{Beban Yang Diperhitungkan}

Pembebanan diperhitungkan sesuai dengan fungsi bangunan yang direncanakan. Perencanaan beban hidup maupun beban mati didasarkan pada tatacara pembebanan untuk bangunan rumah dan gedung[22]. 


\subsection{Metode Perhitungan}

Perhitungan pelat dan balok berdasarkan standar tata cara perhitungan struktur beton yaitu SK SNI 2847, 2013 dan dasar - dasar perencanaan beton bertulang. Sedangkan untuk perhitungan tulangan dilakukan dengan cara teori kekuatan terbatas. Dan Perhitungan portal utama yang terdiri dari balok dan kolom dianalisa dengan menggunakan Metode MomenUltimit. Adapun dasar perhitungan konstruksi untuk portal utama dan elemen-elemen yang lain seperti pelat balok tangga dan lainnya menggunakan SKSNI 2847,2013[23].

\subsection{Perencanaan Beton Bertulang}

Meliputi Pembebanan (Beban mati dan Beban hidup), Asumsi Perletakan (Tangga, Pelat lantai, Balok anak dan Portal), Analisa struktur menggunakan SK SNI 2847 2013, serta Analisa tampang meggunakan peraturan SNI2847 2013. 


\subsection{Metodologi Perencanaan}

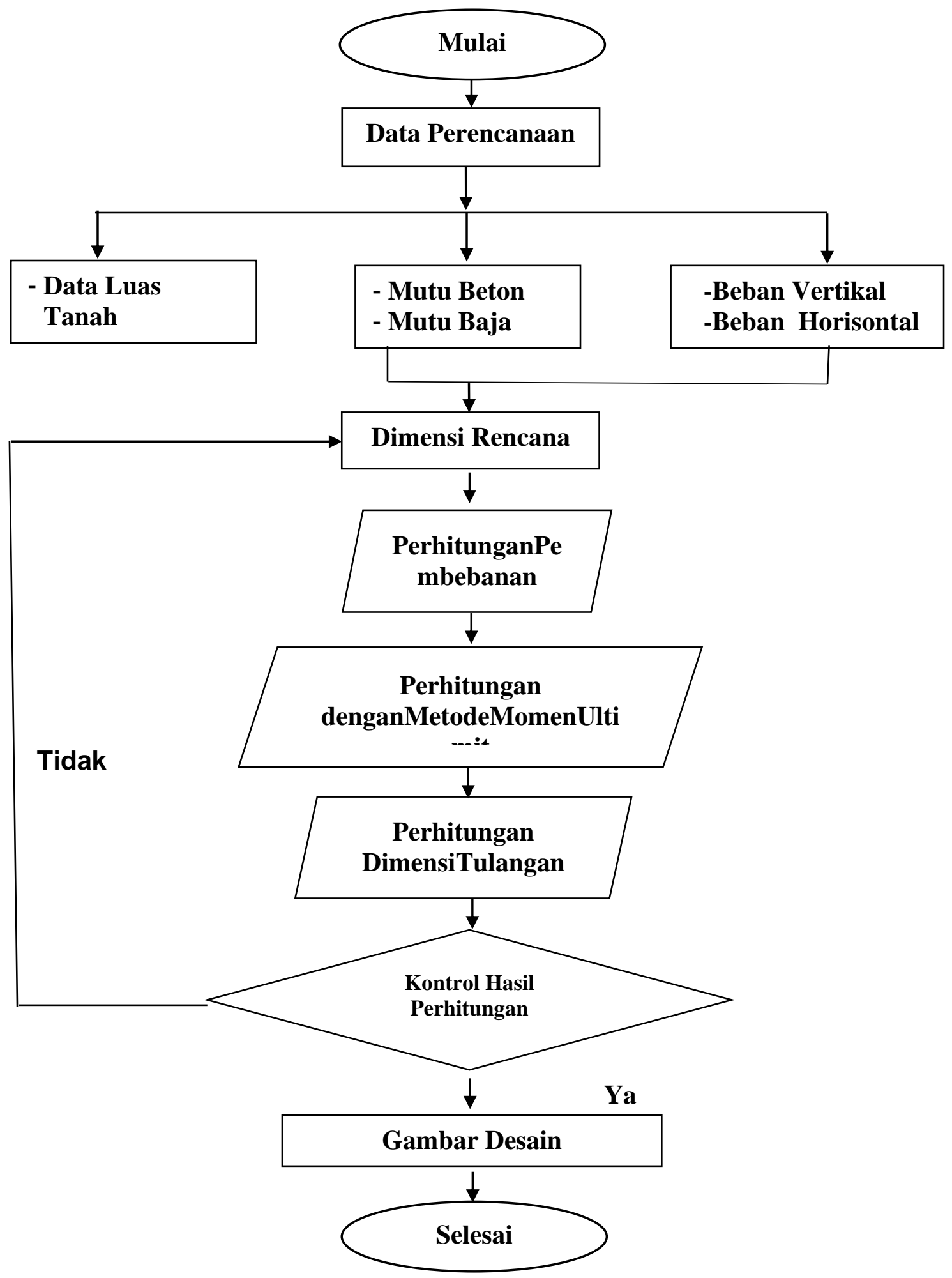

Gambar 1.1 Bagan AlirPerencanaan 


\section{HASIL DAN PEMBAHASAN}

\subsection{Hasil Perhitungan Pembebanan}

Hasil analisa dan Pembahasan pada struktur gedung asrama putri disesuaikan dengan tata cara perhitungan Struktur Beton untuk Gedung bertingkat menggunakan SNI (SK SNI $2847,2013)$, dan tata cara perencanaan pembebanan untuk rumah dan Gedung mengunakan (SKSNI 2847, 2013)

\subsection{Daftar distribusi beban dari lantai 1-7 (atap)}

$\begin{array}{lll}\text { Pelat Atap } & =20.640,924 & \mathrm{Kg} \\ \text { Lantai 6 } & =23.233,644 & \mathrm{Kg} \\ \text { Lantai 5 } & =23.233,644 & \mathrm{Kg} \\ \text { Lantai 4 } & =23.233,644 & \mathrm{Kg} \\ \text { Lantai 3 } & =23.233,644 & \mathrm{Kg} \\ \text { Lantai 2 } & =23.233,644 & \mathrm{Kg} \\ \text { Lantai 1 } & =23.233,644 & \mathrm{Kg}\end{array}$

3.3 Nilai rincian momen yang terjadi pada pelat, balok, kolom

$\begin{array}{llll}\text { Pelat } & & =17.074,370 & \text { Kgm } \\ \text { Balok } & 5 \mathrm{~m} & =342.733,875 & \mathrm{Kgm} \\ & 6 \mathrm{~m} & =493,536,78 & \mathrm{Kgm} \\ \text { Kolom } & & =551.697,600 & \mathrm{Kgm} \\ \text { Sloof } & 5 \mathrm{~m} & =134.131,600 & \mathrm{Kgm} \\ & 6 \mathrm{~m} & =194.092,200 & \mathrm{Kgm}\end{array}$

\subsection{Hasil perencanaan perhitungan tulangan}

Pelat :

Tulangan pokok $: 12 \mathrm{~mm}$

Tulangan sengkang/ bagi $\quad: 8 \quad \mathrm{~mm}$

Jarak sengkang/ bagi $\quad: 200 \mathrm{~mm}$

Balok :

Tulangan Pokok $: 16 \quad \mathrm{~mm}$

Tulangan sengkang/ bagi $\quad: 10 \quad \mathrm{~mm}$

Jarak sengkang/ bagi $\quad: 200 \quad \mathrm{~mm}$

Kolom :

Tulangan pokok

$: 16 \quad \mathrm{~mm}$ 


$\begin{array}{lll}\text { Tulangan sengkang/ bagi } & : 12 & \mathrm{~mm} \\ \text { Jarak sengkang/ bagi } & : 200 & \mathrm{~mm} \\ \text { Sloof : } & & \\ \text { Tulangan pokok } & : 16 & \mathrm{~mm} \\ \text { Tulangan Sengkang/ bagi } & : 10 & \mathrm{~mm} \\ \text { Jarak Sengkang/ bagi } & : 200 & \mathrm{~mm}\end{array}$

\section{KESIMPULAN DAN SARAN}

\subsection{Kesimpulan}

1. Sebelum melakukan perencanaan dan perancangan struktur alangkah lebih tepat apabila memahami lebih dahulu standatr yang berlaku khusunya SNI ( $S K \quad S N I$ 2847,2013)mengenai tata cara perhitungan struktur beton untuk bangunan gedung.

2. Untuk mendapat dan mempercepat perhitungan yang akurat hendaknya menggunakan aplikasi Microsoft Excel. Untuk analisa pembebanan sebaiknya menggunakan perhitungan aplikasi dan perhitungan manual agar hasil yang di peroleh lebih akurat.

\subsection{Saran}

1. Sebelum perencanaan struktur sebaiknya dilakukan estimasi awal pada ukuran elemen struktur, sehingga tidak terjadi penentun elemen struktur berulang - ulang.

2. Dalam perencanaan elemen-elemen struktur seperti penentuan tulangan pelat,balok, serta kolom sebaiknya digunakan ukuran yang hampir seragam untuk mempermudah pelaksanaan pekerjaan di lapangan.

\section{UCAPAN TERIMAKASIH}

Dalam penyusunan artikel ini, penulis ucapkan terimakasih kepada dosen pembimbing dan Universitas Kadiri. Penulis berharap agar artikel ini dapat bermanfaat bagi pembaca.

\section{DAFTAR PUSTAKA}

[1] S. N. Indonesia, "Tata Cara Perhitungan Struktur Beton untuk Bangunan Gedung," Badan Stand. Nasional, Puslitbang pemukiman, Bandung, 2002.

[2] B. S. Nasional, "Tata cara perhitungan harga satuan pekerjaan beton pracetak untuk konstruksi bangunan gedung,” Jakarta Badan Standarisasi Nas., 2012.

[3] W. Hadi Pratomo, "Struktur Beton Prategang (Teori dan Prinsip Desain)," Nova, 1994.

[4] C.-K. Wang, B. Hariandja, and C. G. Salmon, Desain beton bertulang. Erlangga, Jakarta, 
1987.

[5] C.-K. Wang, C. G. Salmon, and B. Hariandja, "Desain Beton Bertulang Jilid 1," Jakarta: Erlangga, 1990.

[6] D. P. Umum, "Peraturan Pembebanan Indonesia untuk Gedung," Bandung: Stensil, 1983.

[7] G. Kusuma, "Dasar-dasar Perencanaan Beton Bertulang Berdasarkan SKSNI T-15-199103 Edisi Kedua.” Erlangga, Jakarta, 1995.

[8] A. I. Candra, "STUDI KASUS STABILITAS STRUKTUR TANAH LEMPUNG PADA JALAN TOTOK KEROT KEDIRI MENGGUNAKAN LIMBAH KERTAS," UKaRsT, vol. 2, no. 2, p. 11, 2018, doi: 10.30737/ukarst.v2i2.255.

[9] F. Febriantoro, Y. C. S. Purnomo, and A. Ridwan, "Study Perencanaan Pondasi Tiang Pancang Jembatan Sembayat Baru II Kecamatan Manyar Kabupaten Gresik,” J. Manaj. Teknol. Tek. Sipil, vol. 1, no. 1, pp. 148-159, 2018, doi: 10.30737/jurmateks.v1i1.147.

[10] D. P. Umum, "Standar Tata Cara Perhitungan Struktur Beton untuk Bangunan Gedung," SK SNI T-15-1991-03, Yayasan LPBM, Bandung, 1991.

[11] A. Setiawan, "Perancangan Struktur Beton Bertulang Berdasarkan SNI 2847 : 2013," pp. $1-2,2016$.

[12] N. Al Amin, "Perencanaan Gedung Sekolah 4 Lantai (1 Basement) Dengan Prinsip Daktail Penuh Di Daerah Sukoharjo.” Universitas Muhammadiyah Surakarta, 2014.

[13] A. I. Candra, "Analisis Daya Dukung Pondasi Strauss Pile pada Pembangunan Gedung Mini Hospital Universitas Kadiri," Ukarst, vol. 1, no. 1, pp. 63-70, 2017.

[14] R. S. Makalalag, "TINJAUAN PERENCANAAN DAN METODE PELAKSANAAN STRUKTUR ATAS PROYEK PEMBANGUNAN KANTOR OTORITAS BANDAR UDARA WILAYAH VIII MANADO TAHAP 2 GEDUNG C.” Politeknik Negeri Manado, 2014.

[15] M. R. Syahputra, G. Yanti, and S. W. Megasari, "PERENCANAAN STRUKTUR BANGUNAN ATAS GEDUNG RUSUNAWA UNIVERSITAS LANCANG KUNING," J. Tek., vol. 11, no. 2, pp. 48-57, 2017.

[16] R. I. A. DEWI SUGIYONO, "ANALISA PERENCANAAN STRUKTUR ATAS JEMBATAN RANGKA BAJA TIPE CAMEL BACK TRUSS,” Rekayasa Tek. Sipil, 
vol. 3, no. 3/REKAT/16, 2016.

[17] S. HADI MURDOKO, “ANALISIS PERENCANAAN STRUKTUR ATAS JEMBATAN BUSUR RANGKA BAJA," Rekayasa Tek. Sipil, vol. 1, no. 1/REKAT/17, 2016.

[18] B. S. Nasional, "Tata cara perencanaan ketahanan gempa untuk struktur bangunan gedung dan non gedung," Sni, vol. 1726, p. 2012, 2012.

[19] M. B. Hanafi, "Perencanaan Struktur Apartemen 5 Lantai+ 1 Basement Dengan Sistem Rangka Pemikul Momen Menengah (SRPMM) Di Sukoharjo.” Universitas Muhammadiyah Surakarta, 2015.

[20] A. R. Julianto, "Perencanaan Ulang Struktur Atas Gedung Laboratorium Sosio Enterpreneurship Universitas Brawijaya Menggunakan Struktur Portal Baja Dengan Penahan Gempa Sistem Bresing Konsentris.” University of Muhammadiyah Malang, 2017.

[21] T. Y. Purnomo, L. D. Krisnawati, and Y. C. S. Purnomo, "Kajian Jembatan Kecamatan Sendang (Ruas Jalan Tugu-Pabyongan) Kabupaten Tulungagung dengan Metode Komposit,” J. Manaj. Teknol. Tek. Sipil, vol. 1, no. 1, pp. 112-125, 2018, doi: 10.30737/jurmateks.v1i1.145.

[22] A. S. N. SAPUTRA, G. WIRATAMA, and I. MUHAMMAD, "PERENCANAAN GEDUNG D KAMPUS IV UNIVERSITAS MUHAMMADIYAH BENGKULU.” POLITEKNIK NEGERI SRIWIJAYA, 2016.

[23] D. A. Andhira, "PERENCANAAN PERHITUNGAN PLAT LANTAI, BALOK DAN KOLOM PADA GEDUNG BERLANTAI III.” undip, 2017. 